nephron

Practice
Nephron 2016;134:25-29

DOI: $10.1159 / 000445450$
Received: February 8, 2016

Accepted after revision: March 12, 2016

Published online: April 7, 2016

\title{
Aging and the Kidneys: Anatomy, Physiology and Consequences for Defining Chronic Kidney Disease
}

\author{
Richard J. Glassock ${ }^{\mathrm{a}}$ Andrew D. Rule ${ }^{\mathrm{b}}$ \\ a David Geffen School of Medicine at UCLA, Los Angeles, Calif., and ${ }^{\mathrm{b}}$ Mayo Clinic, \\ Rochester, Minn., USA
}

\section{Key Words}

Aging $\cdot$ Glomerular filtration rate $\cdot$ Chronic renal disease

\begin{abstract}
The varied functions of the kidneys are influenced by the complex process of aging. The glomerular filtration rate (GFR) steadily declines with normal aging, and the progress of this process can be influenced by superimposed diseases. Microscopically, nephron numbers decrease as global glomerulosclerosis becomes more evident. The precise mechanisms underlying nephron loss with aging are not well understood, but derangements in podocyte biology appear to be involved. Classifications of chronic kidney disease (CKD) incorporate GFR values and attendant risk of adverse events. Arbitrary and fixed thresholds of GFR for defining CKD have led to an overdiagnosis of CKD in the elderly. An age-sensitive definition of CKD could offer a solution to this problem and more meaningfully capture the prognostic implications of CKD.
\end{abstract}

(c) 2016 S. Karger AG, Basel

Contribution from the Special Symposium to celebrate the contributions of David G. Warnock, MD to Academic Nephrology, The University of Alabama at Birmingham, Division of Nephrology, November 9, 2015.

\section{KARGER}

(c) 2016 S. Karger AG, Basel

E-Mail karger@karger.com

www.karger.com/nef

\section{Introduction}

Aging is a complex and poorly understood process that involves genes, environment and chance [1]. While few patients truly die from 'old age' alone, age is a strong independent contributor to mortality. Aging proceeds at variable rates, even among members of the same and identical animal species. Aging is fundamentally due to cellular degeneration (senescence) and faulty repair. It seems to be inevitable in nearly all species, with the possible exception of the genus Hydra [1]. All of the organs and organ systems of humans exhibit the consequences of aging, but this brief review will focus mainly on the kidneys, specifically the glomeruli and their function (glomerular filtration rate; GFR). Several other functions of the kidneys, such as urine concentration and dilution and sodium and potassium homeostasis, can also be influenced by the aging process (see [2] for a review), but will not be discussed here.

\section{Changes in GFR and Kidney Anatomy with Aging}

Both GFR and renal plasma flow (RPF) decline with adult aging, beginning at about age $30[2,3]$. Around the time one is 80 years old, the RPF declines more rapidly than GFR, leading to a modest increase in filtration fraction. The average yearly decline of GFR between age 30 and 75 in

\footnotetext{
Dr. Richard J. Glassock

David Geffen School of Medicine at UCLA

8 Bethany, Laguna Niguel

Los Angeles, CA 92677 (USA)

E-Mail glassock@cox.net
} 
otherwise healthy individuals is about $0.7-0.9 \mathrm{ml} / \mathrm{min}[3$, 4]. The rate of decline may increase with superimposition of various diseases (e.g. hypertension, diabetes, prostatism) on the aging process per se $[4,5]$. Disentangling the effects of aging itself on GFR from that of superimposed diseases can be very challenging. After about age 75 the rate of decline of GFR may accelerate, but still does not progress fast enough to cause kidney failure in the human life span [6].

The normal GFR in a healthy adult male at age 20 is about $100-110 \mathrm{ml} / \mathrm{min} / 1.73 \mathrm{~m}^{2}$ and can decline to $<60$ $\mathrm{ml} / \mathrm{min} / 1.73 \mathrm{~m}^{2}$ in a variable fraction $(5-25 \%)$ of otherwise healthy adults after age 60-65, depending on gender and attained age $[3,7]$. The frequency distribution of GFR remains approximately Gaussian at all ages, in otherwise healthy subjects $[4,8]$. The decline of GFR with aging is independent of blood pressure in healthy nonhypertensive individuals [5], and occurs even in indigenous populations free of cardiovascular disease [9].

The fundamental origins of the declining GFR with healthy aging are not fully understood. However, studies of healthy living kidney transplant donors (by the Stanford and Mayo Clinic groups) have contributed much to elucidate possible pathways [10-12]. With aging, the kidney cortical volume decreases (in parallel with declining GFR), while the medullary volume increases offsetting to some extent the impact of reduced cortical volume on overall kidney volume [13]. Microscopically, kidney aging is characterized by nephrosclerosis: increasing focal and global (not segmental) glomerulosclerosis (FGGS), interstitial fibrosis/tubule atrophy and arteriolosclerosis [14]. The clinical importance of this glomerulosclerosis, in particular, may be different in 'healthy' aging compared to diseaseinduced pathology [15]. In 'healthy' aging, the rate of decline of GFR is not correlated with the extent of nephrosclerosis - a decline in GFR of about $0.63 \mathrm{ml} / \mathrm{min} / 1.73 \mathrm{~m}^{2}$ per year is seen regardless of the sclerosis score on renal biopsy in living donors at any age [16]. The density of nonsclerotic glomeruli decreases by $7 \%$ per decade, while the density of FGGS increases by $14 \%$ per decade [14]. These microscopic findings suggest that the decline in GFR seen with aging is a phenomenon related to a slowly progressive loss of nephrons from age 30 onward. Compensatory hypertrophy of residual nonsclerotic glomeruli and their attached tubules (nephron hypertrophy) may explain the reduced glomerular density seen in renal biopsies with aging; however, causality should be inferred only from cross-sectional findings with caution. The precise mechanisms responsible for FGGS is also unknown, but animal experimentation and human studies suggest that visceral epithelial cell degeneration (apoptosis and detachment) and faulty replacement from parietal epithelial cells progenitors may be operating [17-19]. The resultant 'podocytopenia' can also influence single nephron filtration rate (SNGFR), by altering hydraulic permeability or the surface area available for filtration [20]. The changes in SNGFR among nonsclerotic glomeruli in human aging remain uncertain due to methodological issues, but if single nephron hyper-filtration occurs in residual nephron secondary to nephron loss, then hemodynamic stress on podocytes could contribute to their degeneration. So far, increased (or decreased) SNGFR has not been observed consistently in aging human kidneys until very advanced ages [21]. Thus, the major changes in whole kidney GFR with aging can be attributed primarily to nephron loss. Since podocytes are nonreplicative, terminally differentiated cells it is unlikely that post-mitotic (Hayflick type) senescence is involved; however, recent studies have shown an increase in podocyte numbers in glomeruli of adults compared to children, so new podocytes might be generated with aging, at least in early years [22]. A major unanswered question is how does nephron endowment at birth affect the physiologic process of loss of GFR with aging. Specifically, would a low nephron endowment at birth (due to fetal undernourishment) result in an acceleration of glomerular aging and an earlier or more prominent decline in GFR with aging?

\section{The Relevance of Aging-Associated Changes in GFR for Diagnosis of CKD and Assessment of Risk of Adverse Events}

According to contemporary schema for classification of chronic kidney disease (CKD; KDIGO, 2012), any subject, regardless of age, with a GFR (measured or estimated) of $<60 \mathrm{ml} / \mathrm{min} / 1.73 \mathrm{~m}^{2}$ sustained for at least 3 months has CKD (Stage 3-5, depending on the magnitude of the decline in GFR $<60 \mathrm{ml} / \mathrm{min} / 1.73 \mathrm{~m}^{2}$ ) irrespective of the presence or absence of other signs of kidney injury (e.g. albuminuria) [23]. As a result, half of adults over age 70 can be 'diagnosed' as having CKD $[24,25]$. This conclusion conflates a reduced GFR with a 'disease,' and presumes that all sustained decreases in GFR $<60 \mathrm{ml} / \mathrm{min} / 1.73 \mathrm{~m}^{2}$ are a manifestation of a disease of the kidneys, even though (as discussed above) this can and does occur in healthy aging. Clearly some elderly adults with reduced GFR do have a kidney disease - one that will more often than not be accompanied by abnormal albumin excretion or an abnormal urinary sediment. A great majority of individuals receiving the 'label' of CKD over age 65-70 years are identified by an 'isolated' decline of eGFR between values of 45 


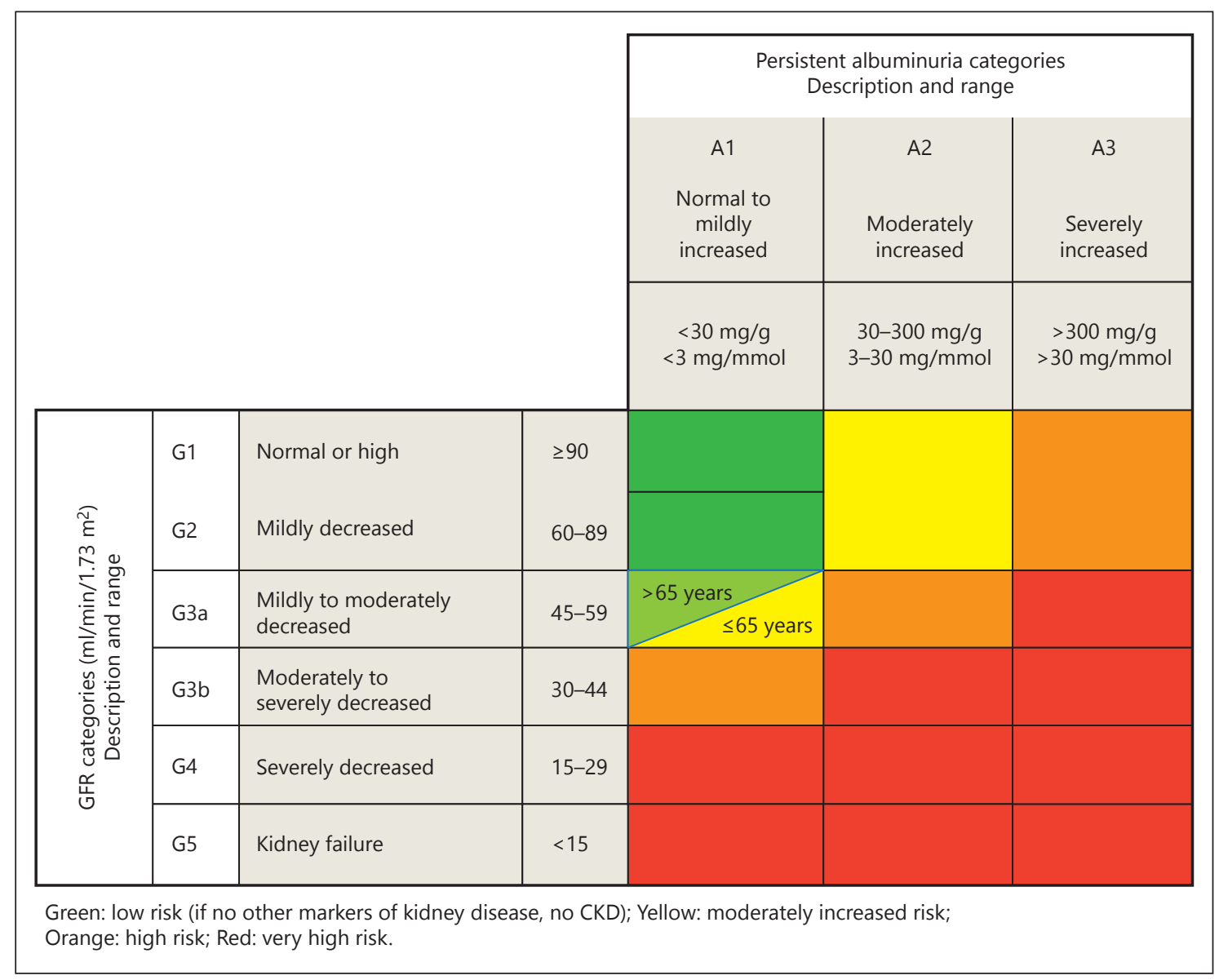

Fig. 1. A proposed age-calibrated classification of CKD based on eGFR, albuminuria and risk of adverse events (adapted from reference [23] - from Glassock R et al. [unpublished]; color schems: green = no CKD or very low risk; yellow $=\mathrm{CKD}$ and low risk; orange $=\mathrm{CKD}$ and moderate risk; red $=\mathrm{CKD}$ and high risk).

and $59 \mathrm{ml} / \mathrm{min} / 1.73 \mathrm{~m}^{2}$ (CKD Stage $3 \mathrm{~A} / \mathrm{A} 1$ by KDIGO criteria), whereas younger subjects usually receive a diagnosis of CKD because of a finding of abnormal proteinuria, rather than reduced eGFR [26]. In the elderly, this has been suggested to be an example of 'overdiagnosis' of CKD due to the inappropriate use of a single, arbitrary and absolute threshold for defining CKD based on measured GFR or eGFR $[27,28]$. It is debatable whether such values of measured GFR or eGFR in older subjects contribute very much to the determination of risks of adverse cardiovascular (CV) events or mortality [29]. Adding GFRbased CKD Stage to standard risk prediction (e.g. Framingham Risk Scores) for CV events does not meaningfully improve classification of risk, and eGFR has not been incorporated into most such scoring systems used widely in clinical practice [29]. Recently, Malmgren et al. [30] have shown in elderly Swedish women that relative mortality risk (fully adjusted for comorbidity) is not associated with
CKD Stage 3A (compared to non-CKD), regardless of the method used to determine eGFR by serum creatininebased equations. In the same study, CKD Stage 3B was strongly associated with enhanced mortality risk (hazard ratio of 2.2-3.5), depending on the eGFR-creatinine formula used. In an exhaustive meta-regression analysis involving the CKD Prognosis Consortium, Hallan et al. [31] showed that the relative risk for all-cause mortality associated with a decline in eGFR (adjusted for albuminuria and comorbidity) is attenuated by age, but that using a common reference point of an eGFR of $80 \mathrm{ml} / \mathrm{min} / 1.73 \mathrm{~m}^{2}$ that morality risk was increased at all ages when eGFR fell below $60 \mathrm{ml} / \mathrm{min} / 1.73 \mathrm{~m}^{2}$. They also showed that such mortality is increased in younger subjects (age 18-54) even when the eGFR is $<75 \mathrm{ml} / \mathrm{min} / 1.73 \mathrm{~m}^{2}$. In a reanalysis of the Hallan et al. [31] data, Denic et al. [8] have shown that the lowest risk range for eGFR decreases from $>75 \mathrm{ml} /$ $\mathrm{min} / 1.73 \mathrm{~m}^{2}$ in younger adults to a range of $45-104 \mathrm{ml} /$ 
$\min / 1.73 \mathrm{~m}^{2}$ in the subjects over 75 years of age. It has been argued that a $20 \%$ higher relative risk of mortality with CKD Stage $3 \mathrm{~A}$ in the elderly is important because it translates into a high absolute risk of mortality [31]. This occurs because of the underlying high mortality rate in the elderly. A CKD classification system justified on how well it detects absolute mortality risk still needs to account for the limited human life expectancy. It also remains debatable as to whether there really is even an increased risk of mortality in all age groups for CKD Stage 3A. Another study found that the remaining life expectancy of subjects over age 30 with CKD Stage $3 \mathrm{~A}$ is not any different than those without CKD [32]. The development of treated endstage renal disease (ESRD) is relatively uncommon in older subjects with CKD Stage $3 \mathrm{~A} / \mathrm{A} 1$, and is at least in part attributed to death before reaching ESRD [33]. Evidence that these older subjects die from their CKD rather than with their CKD is lacking.

Based on these considerations, a proposal has been advanced to modify the risk stratification (also called a 'heat map') for individuals above and below the age of 65 [23] (fig. 1). If this proposal were adopted, the prevalence of prognosis (risk)-stratified CKD in general adult populations might decline from about $11-13$ to $5 \%$ or less, and referrals for evaluation of 'supposed' CKD in the elderly could be reduced by $70 \%$ or even more. 'Overdiagnosis' of CKD in the elderly is largely avoidable if assessment of risk-based criteria for diagnosis is calibrated in an age- sensitive manner. Such a suggestion does not deny the theoretical value of determining eGFR or mGFR to avoid overdosing water-soluble drugs excreted mainly by GFR, though this should be proven by prospective controlled trials rather than simply assumed.

\section{Conclusions}

Aging of an organism proceeds at variable rates, as influenced by genes, environment and chance. The kidneys participate in this physiologic process, and one manifestation is a decline in GFR, usually beginning after age 30 . This process appears to be due to a steady loss of nephrons from global glomerulosclerosis perhaps as a result of visceral glomerular podocyte degeneration and inadequate repair. Such a physiological decline in GFR with aging has important ramifications for diagnosis of CKD and in the estimation of risks for adverse events, including mortality. We contend that the current schema for classification of CKD based on GFR should be redesigned to be age-calibrated. This would better reflect both the underlying biology of the aging kidney and the risks of mortality and ESRD.

\section{Disclosure Statement}

The authors have no conflicts of interest to declare.

\section{References}

1 Finch CE, Kirkwood TBL: Chance, Development and Aging. Oxford, Oxford University Press, 2000.

2 Epstein M: Aging and the kidney. J Am Soc Nephrol 1996;7:1106-1122.

3 Glassock RJ, Rule AD: The kidney in aging; in Davison AM, Cameron S, Grunfeld J-P, Ponticelli C (eds): Oxford Textbook of Clinical Nephrology, ed 3. Oxford, Oxford University Press, 2015.

4 Lindeman RD, Tobin J, Shock NW: Longitudinal studies on the rate of decline in renal function with age. J Am Geriatr Soc 1985;33: 278-285.

5 Lindeman RD, Tobin JD, Shock NW: Association between blood pressure and the rate of decline in renal function with age. Kidney Int 1984;26:861-868.

6 Rowe JW, Andres R, Tobin JD, Norris AH, Shock NW: The effect of age on creatinine clearance in men: a cross-sectional and longitudinal study. J Gerontol 1976;31:155-163.

7 Poggio ED, Rule AD, Tanchanco R, Arrigain S, Butler RS, Srinivas T, Stephany BR, Meyer
KH, Nurko S, Fatica RA, Shoskes DA, Krishnamurthi V, Goldfarb DA, Gill I, Schreiber MJ Jr: Demographic and clinical characteristics associated with glomerular filtration rates in living kidney donors. Kidney Int 2009;75: 1079-1087.

8 Denic A, Glassock RJ, Rule AD: Structural and functional changes with the aging kidney. Adv Chronic Kidney Dis 2016;23:19-28.

9 Hollenberg NK, Rivera A, Meinking T, Martinez G, McCullough M, Passan D, Preston M, Taplin D, Vicaria-Clement M: Age, renal perfusion and function in island-dwelling indigenous Kuna Amerinds of Panama. Nephron 1999;82:131-138.

10 Tan JC, Busque S, Workeneh B, Ho B, Derby G, Blouch KL, Sommer FG, Edwards B, Myers BD: Effects of aging on glomerular function and number in living kidney donors. Kidney Int 2010;78:686-692.

11 Hoang K, Tan JC, Derby G, Blouch KL, Masek M, Ma I, Lemley KV, Myers BD: Determinants of glomerular hypofiltration in aging humans. Kidney Int 2003;64:1417-1424.
12 Glassock RJ, Rule AD: The implications of anatomical and functional changes of the aging kidney: with an emphasis on the glomeruli. Kidney Int 2012;82:270-277.

13 Wang X, Vrtiska TJ, Avula RT, Walters LR, Chakkera HA, Kremers WK, Lerman LO, Rule AD: Age, kidney function, and risk factors associate differently with cortical and medullary volumes of the kidney. Kidney Int 2014;85:677-685.

14 Kremers WK, Denic A, Lieske JC, Alexander MP, Kaushik V, Elsherbiny HE, Chakkera HA, Poggio ED, Rule AD: Distinguishing agerelated from disease-related glomerulosclerosis on kidney biopsy: the aging kidney anatomy study. Nephrol Dial Transplant 2015;30: 2034-2039.

-15 Elsherbiny HE, Alexander MP, Kremers WK, Park WD, Poggio ED, Prieto M, Lieske JC, Rule AD: Nephron hypertrophy and glomerulosclerosis and their association with kidney function and risk factors among living kidney donors. Clin J Am Soc Nephrol 2014;9:18921902. 
16 Rule AD, Amer H, Cornell LD, Taler SJ, Cosio FG, Kremers WK, Textor SC, Stegall MD: The association between age and nephrosclerosis on renal biopsy among healthy adults. Ann Intern Med 2010;152:561-567.

17 Roeder SS, Stefanska A, Eng DG, Kaverina N, Sunseri MW, McNicholas BA, Rabinovitch P, Engel FB, Daniel C, Amann K, Lichtnekert J, Pippin JW, Shankland SJ: Changes in glomerular parietal epithelial cells in mouse kidneys with advanced age. Am J Physiol Renal Physiol 2015;309:F164-F178.

18 Pippin JW, Glenn ST, Krofft RD, Rusiniak ME, Alpers CE, Hudkins K, Duffield JS, Gross KW, Shankland SJ: Cells of renin lineage take on a podocyte phenotype in aging nephropathy. Am J Physiol Renal Physiol 2014; 306:F1198-F1209.

19 Shankland SJ, Anders HJ, Romagnani P: Glomerular parietal epithelial cells in kidney physiology, pathology, and repair. Curr Opin Nephrol Hypertens 2013;22:302-309.

20 Tan JC, Workeneh B, Busque S, Blouch K, Derby G, Myers BD: Glomerular function, structure, and number in renal allografts from older deceased donors. J Am Soc Nephrol 2009;20:181-188.

21 Denic A, Lerman LO, Lieske JC, Alexander MP, Chakkera HA, Poggio ED, Glassock RJ, Rule AS: Clinical characteristics associate differently with single nephron GFR than total GFR in normal adults. J Am Soc Nephrol 2015:205A

-22 Puelles VG, Douglas-Denton RN, CullenMcEwen LA, Li J, Hughson MD, Hoy WE,
Kerr PG, Bertram JF. Podocyte number in children and adults: associations with glomerular size and numbers of other glomerular resident cells. J Am Soc Nephrol 2015;26: 2277-2288.

23 Kidney Disease Improving Global Outcomes: KDIGO 2012 clinical practice guideline for the evaluation and management of chronic kidney disease. Kidney Int Suppl 2013;3:1150.

24 Coresh J, Selvin E, Stevens LA, Manzi J, Kusek JW, Eggers P, Van Lente F, Levey AS: Prevalence of chronic kidney disease in the United States. JAMA 2007;298:2038-2047.

25 Schaeffner ES, Ebert N, Delanaye P, Frei U, Gaedeke J, Jakob O, Kuhlmann MK, Schuchardt M, Tolle M, Ziebig R, van der Giet M, Martus P: Two novel equations to estimate kidney function in persons aged 70 years or older. Ann Intern Med 2012;157:471-481.

26 James MT, Hemmelgarn BR, Tonelli M: Early recognition and prevention of chronic kidney disease. Lancet 2010;375:1296-1309.

27 Moynihan R, Glassock R, Doust J: Chronic kidney disease controversy: how expanding definitions are unnecessarily labelling many people as diseased. BMJ 2013;347:f4298.

28 Glassock R, Delanaye P, El Nahas M: An agecalibrated classification of chronic kidney disease. JAMA 2015;314:559-560.

29 Clase CM, Gao P, Tobe SW, McQueen MJ, Grosshennig A, Teo KK, Yusuf S, Mann JF; ONTARGET (Ongoing Telmisartan Alone and in Combination with Ramipril Global Endpoint Trial) and TRANSCEND (Telmis- artan Randomized Assessment Study in Angiotensin-Converting-Enzyme-Inhibitor Intolerant Subjects with Cardiovascular Disease): Estimated glomerular filtration rate and albuminuria as predictors of outcomes in patients with high cardiovascular risk: a cohort study. Ann Intern Med 2011;154:310318

30 Malmgren L, McGuigan FE, Berglundh S, Westman K, Christensson A, Åkesson K: Declining estimated glomerular filtration rate and its association with mortality and comorbidity over 10 years in elderly women. Nephron 2015;130:245-255.

31 Hallan SI, Matsushita K, Sang Y, Mahmoodi BK, Black C, Ishani A, Kleefstra N, Naimark D, Roderick P, Tonelli M, Wetzels JF, Astor BC, Gansevoort RT, Levin A, Wen CP, Coresh J; Chronic Kidney Disease Prognosis Consortium: Age and association of kidney measures with mortality and end-stage renal disease. JAMA 2012;308:2349-2360.

32 Gansevoort RT, Correa-Rotter R, Hemmelgarn BR, Jafar TH, Heerspink HJ, Mann JF, Matsushita K, Wen CP: Chronic kidney disease and cardiovascular risk: epidemiology, mechanisms, and prevention. Lancet 2013; 382:339-352.

33 O'Hare AM, Hotchkiss JR, Kurella Tamura M, Larson EB, Hemmelgarn BR, Batten A, Do $\mathrm{TP}$, Covinsky KE: Interpreting treatment effects from clinical trials in the context of realworld risk information: end-stage renal disease prevention in older adults. JAMA Intern Med 2014;174:391-397. 